\title{
VOZES DA BASILEIA: O REINO \\ DE DEUS COMO KERIGMA FEMININO \\ NO EVANGELHO LUCANO
}

\author{
Danilo Dourado Guerra*
}

\section{RESUMO}

Este artigo tem como objeto embrionário de investigação o anúncio do Reino de Deus por parte das discípulas de Jesus em Lucas 8,1-3. Dentro de nossa propositiva, pretendemos demostrar que apesar, da práxis de ocultação e silenciamento da voz das seguidoras de Jesus, o kerigma feminino da basileia explícito na narrativa lucana reflete uma ruptura paradigmática significativa, tanto em relação ao sistema patriarcal da época, quanto no tocante as políticas de interpretação de textos bíblicos de matiz androcêntrica estruturadas ao longo dos tempos.

Palavras-chave: Reino de Deus. Hermenêutica feminista. Evangelho de Lucas. Heterotopia.

\section{VOICES OF BASILEIA: THE KINGDOM OF GOD AS FEMININE KERIGMA IN THE LUCAN GOSPEL}

\section{ABSTRACT}

This article has object embryonic of investigation the announcement of the Kingdom of God on the part of the disciples of Jesus in Luke 8,1-3. Within our proposition, we intend to show that despite the praxis of concealment and silence of the followers of Jesus, the feminine kerygma of the basileia explicit in the Lucan narrative reflects a significant paradigmatic rupture, both in relation to the patriarchal system of the time, and in relation to the politics of Interpretation of biblical texts of androcentric hue structured throughout the ages.

Keywords: Kingdom of God. Feminist hermeneutics. Gospel of Luke. Heterotopia.

* Doutorado (2018) e Mestrado (2015) em Ciências da Religião pela Pontifícia Universidade Católica de Goiás, com estágio doutoral sanduíche na Università Degli Studi di Padova, Itália (2017). Bolsista CAPES PROSUC/PDSE. Bacharel em Teologia pelo Seminário Teológico Batista Nacional (SETEBAN-GO) e pela Faculdade da Igreja Ministério Fama (FAIFA). 


\section{VOCES DE LA BASILEA: EL REINO DE DIOS COMO KERIGMA FEME- NINO EN EL EVANGELIO LUCANO}

\section{RESUMEN}

Este artículo tiene como objeto embrionario de investigación el anuncio del Reino de Dios por parte de las discípulas de Jesús en Lucas 8,1-3. Dentro de nuestra propositiva, pretendemos demostrar que a pesar de la praxis de ocultación y silenciamiento de la voz de las seguidoras de Jesús, el kerigma femenino de la basilea explícita en la narrativa lucana refleja una ruptura paradigmática significativa, tanto en relación al sistema patriarcal de la época, como en lo tocante a las políticas de interpretación de textos bíblicos de matiz androcéntrico estructuradas a lo largo de los tiempos.

Palabras-clave: Reino de Dios. Hermenéutica feminista. Evangelio de Lucas. Heterotopia.

\section{INTRODUÇÃO}

Começaremos nossa prédica apresentando-vos a voz. Instrumento que produz sonoridades em várias frequências, timbres, tonalidades e tensões. Imprescindível no mundo das (inter)relações humanas. Ao longo dos tempos, esta tem sido utilizada através das palavras e signos como ferramenta de comunicação e transmissão das mais diversas mensagens relacionadas às experiências, vivências, alegrias e dramas da humanidade. Nesse enredo de circularidades do poder (Michel FOUCAULT, 2012), a voz tem sido utilizada no enquadramento dos arranjos societais, de um lado, como instrumento de encantamento das massas, do outro, como dispositivo de empoderamento crítico e heterotópico ${ }^{1}$ em relação às dinâmicas de opressão vigentes, esta última, tornando-se alvo de políticas interpretativas de ocultação e silenciamento físico e simbólico (Pierre BOURDIEU, 2003).

\footnotetext{
“As heterotopias são: Lugares reais, lugares efetivos, lugares que são delineados na própria instituição da sociedade, e que são espécies de contraposicionamentos, espécies de utopias efetivamente realizadas nas quais os posicionamentos reais que podem se encontrar no interior da cultura estão ao mesmo tempo representados, contestados e invertidos, espécies de lugares que estão fora de todos os lugares, embora eles sejam efetivamente localizáveis" (Michel FOUCAULT, 2009, p. 415).
} 
Quando nos referimos, especificamente, à voz feminina na antiguidade, adentramos em um locus histórico efeitual (Hans-Georg GADAMER, 1997) repleto de engrenagens invisibilizatórias e silenciantes oriundas de um diagrama societal predominantemente patriarcal. Sob esse prisma, traçar um perfil histórico da mulher na antiguidade é algo extremamente complexo, visto que os registros sobre ela em sua maioria procedem de um ponto de vista aristocrático e patriarcal (Marina CAVICCHIOLI, 2003). Dessa forma, a história antiga tem sido basicamente o estudo da elite, visto que é nesse estrato social que temos o maior número de informações (Sara POMEROY apud Ana Teresa GONÇALVES, 2003, p. 330). Ao constatarmos o fato de uma história sobre a mulher da antiguidade construída sob a face elitista, observamos a problemática da invisibilização das outras possibilidades e do silenciamento de prováveis vozes dissonantes a essas perspectivas.

Este cenário, por seu turno, nos encaminha para os dias de Jesus e de seus discípulos(as), estruturados na tessitura neotestamentária. Nesse contexto, o Evangelho de Lucas apresenta perspectivas otimistas em relação ao protagonismo das mulheres no movimento de Jesus dentro do panorama dos cristianismos originários. No entanto, olhares e juízos interpretativos sobre elas sempre existiram, principalmente fundamentados na já referida estrutura patriarcal estabelecida ao longo dos tempos e das sociedades.

Compreendemos que, em nossos processos interpretativos, ouvimos e damos voz a aquilo ou a quem nos interessa. Assim, neste texto, a partir de reflexões e questionamentos, de forma parcial e fragmentária, procuraremos remover o 'suposto' silêncio das mulheres seguidoras de Jesus em relação à proclamação do Reino de Deus a partir da narrativa de Lucas 8,1-3. Acreditamos que a voz feminina sempre existiu; o que precisamos é nos prestar a ouvi-la e com isso admiti-la como construtora do seu próprio destino.

Ser mulher nunca foi algo fácil, pelo menos à medida que olhamos para as supostas identidades e para os supostos papéis estabelecidos para elas ao longo dos processos históricos e interpretativos da humanidade. Quando nos aludimos, então, à vida das mulheres no contexto dos cristianismos originários, nos deparamos com uma situação de 
contrastes e rupturas em relação a paradigmas encontrados em um panorama social patriarcal (Ivoni RICHTER REIMER, 2005) em todas as suas esferas ${ }^{2}$. Da mesma forma, quando discorremos sobre a proposta de um Reino divino trazido por Jesus, o vemos em uma situação de conflito com as mesmas engrenagens de dominação.

Segundo Luise Schottroff (2008, p. 165), o Novo Testamento é uma fonte importante para história feminina, pois ele "demonstra, em contextos bastante diversos que no cristianismo primitivo existia uma vida social e comunitária de mulheres". Nessa cena escriturística, as muIheres possuem múltiplos perfis ${ }^{3}$ e múltiplas possibilidades, no sentido da construção de sua própria vida. "Nem tudo, porém, é harmonia". Há muitos conflitos (Ivoni RICHTER REIMER, 2013, p. 80).

É sobre esse viés conflitual que pretendemos abordar a temática do Reino de Deus dentro do Evangelho de Lucas, especificamente em Lc 8,1-3. No entanto, observaremos a narrativa lucana sob a ótica da suspeita ${ }^{4}$ (Elisabeth SCHÜSSLER FIORENZA, 2005), proporcionada pela utilização de uma hermenêutica feminista, na tentativa de visibilizar a atividade e a vida de mulheres em prol de um Reino que não celebra as diferenças, mas as questiona e visa transformá-las.

\section{O CARÁTER LIBERTADOR DO REINO DE DEUS}

Antes de tratarmos acerca do reino de Deus no contexto lucano, algo primordial a ser considerado é que os ideários do 'reino' (basileia) ou do 'reino de Deus' (basileia tou theou) não têm sua gênese nos discursos de Jesus, mas sim, possuem origem, história e conceituações

\footnotetext{
2 "A visão da vida comunitária feminina, proporcionada pelo Novo Testamento, está presente em todas áreas da vida. No trabalho (Mt 24,41 par.), na relação solidária de vizinhas (LC 15,9), nas ruas (1 Tm 5,13; Lc 8, 1-3; Mc 15.40s par.), nas liturgias judaicas (At 16,13) e cristãs (1 Co 11,5; 14,34)" (Luise SCHOTTROFF, 2008, p. 166).

3 De acordo com Ivoni Richter Reimer (2013, p. 80) "o quadro que se apresenta mostra que mulheres fazem parte da multidão, estão ativas nas ruas, nas casas, na sinagoga e no templo. São esposas, mães, viúvas e celibatárias. São mulheres judias, gregas, egípcias, asiáticas, macedônias... São artesãs, comerciantes, confeccionam perfumes, roupas, tendas; são profetisas, diaconisas, missionárias, discípulas, apóstolas; são divindades femininas, hereges, santas e prostitutas. Enfim, por meio de textos do Novo Testamento, temos uma ampla exposição das multifacetárias situações e condições de vida de mulheres daquele tempo".

4 Sobre a hermenêutica da suspeita ver em Elisabeth Schüssler Fiorenza (2009, p. 197-199).
} 
particulares, que, por sua vez, estão densamente condensados à trajetória do povo judeu e ao panorama histórico-social veterotestamentário (Emilio NúÑEZ, 1975).

Do ponto de vista semântico, podemos dizer que no Antigo Testamento, o símbolo do reino de Deus encontra-se originariamente relacionado à confissão israelita acerca da soberania essencial de Deus (Senén VIDAL, 2009, p. 103). Nesse ato confessional, o reino divino exprime-se, especialmente, a partir dos predicados atribuídos a Deus e dos verbos que expressam sua ação. À luz dessa diagramação conceitual, Yahveh é designado, sobretudo como rei5 (Jacques SCHLOSSER, 2004, p. 1501). Em síntese, através do conceito 'reino de Deus', “procura-se expressar uma forma de governo ou reinado de Yahveh sobre determinada grandeza social, área geográfica ou cosmo como um todo" (Haroldo REIMER; Ivoni RICHTER REIMER, 2008, p. 855-856). Sob essa perspectiva, apesar das ambiguidades que envolvem o termo basileia (hebraico: malkut), este, em suma "sugere a ideia de um território ou comunidade governada por um rei" (Charles DODD, 1974, p. 42).

Por sua parte, no tocante ao contexto neotestamentário, o Reino de Deus se constitui no tema central da pregação de Jesus (Joachim JEREMIAS, 1973; Rudolf BULTMANN, 1981; Bruce MALINA, 2004), e, consequentemente em uma das principais temáticas analisadas pela teologia moderna6. A expressão Reino de Deus provém de Jesus, pois fora dos Evangelhos sinóticos, com exceções visíveis no corpus literário joanino (Danilo GUERRA, 2015; 2018), quase que inexiste no Novo Testamento (Leonhard GOPPELT, 2003). Dessa forma, é de longe nos sinóticos que a temática recebe maior atenção com (111 das 144 ocorrências ${ }^{7}$ dentro do

\footnotetext{
5 "No Antigo Testamento, a ideia de um reino de Deus vem expressa através do verbo malak / 'reinar' associado com o nome Yahveh (SI 93.1; 96.10; Êx 15.18; 1Sm 8.7; Is 24.23; etc). Em vários textos, Yahveh também recebe o título de melek / 'rei' (Nm 23.21; Dt 33.5; Is 6.5; 41.21; 43.15 etc). Somente em poucos textos aparece a designação malkut Yhwh / 'reinado de Yahveh' (SI 103.19; 145.11-13)"(Haroldo REIMER e Ivoni RICHTER REIMER, 2008, p. 855).

6 Muitos estudiosos já pesquisaram e refletiram sobre o Reino de Deus que visto como conteúdo central da mensagem cristã se encontra na linha que parte desde Kant, Schleiermacher no século XXVIII a Albrecht Ritschl no século XIX.

7 Acerca do uso e significado do Reino de Deus em Paulo ver Haroldo Reimer e Ivoni Richter Reimer (2008, p. 858s).
} 
N.T.). Dentre essas inúmeras menções, o Evangelho de Lucas é detentor de 43 delas, geralmente utilizando a forma basileia ${ }^{8}$ tou theou (Lothar COENEN e Colin BROWN, 2000, p. 2035).

Na esfera neotestamentária, o Reino de Deus se faz uma chamada para uma decisão e conversão dos seres humanos (Rudolf SCHNAKENBURG, 1967; Rudolf BULTMANN, 1981; Haroldo REIMER e Ivoni RICHTER REIMER, 2008). Nesse sentido, compreendemos a basileia tou theou como o domínio de um rei (Oliver BUSWELL, 2005), o governo de Deus que põe fim ao atual curso do mundo e a toda tristeza e sofrimento, trazendo salvação ao seu povo (Rudolf BULTMANN, 1981). Esse Reino é a consumação escatológica9 ${ }^{9}$ da soberania histórico-libertadora de Deus (Jürgen MOLTMANN, 1978, p. 232). O mesmo conserva em si um caráter de universalidade e totalidade e se historifica pela liberdade, conversão e não pela opressão (Leonardo BOFF, 2012), designando a revelação última e definitiva da glória de Deus (Joachim JEREMIAS, 1973).

Segundo Wolfhart Pannenberg (1974), a basileia tou theou é uma realidade mais concreta que se pode pensar de amor e direito entre os seres humanos. Nela, justiça e amor não se relacionam apenas com indivíduos, mas com as estruturas de convivência social. Nesse aspecto, o Reino de Deus tem caráter decididamente político. Sob esse prisma, um dos princípios fundamentais do Reino é a sua realidade crítica e subversiva. No exercício de sua soberania, Deus, de forma antagônica, critica os tipos de governo que excluem, oprimem e desumanizam o ser humano. Dessa forma, proclamar a soberania de Deus em termos

\footnotetext{
A palavra grega basileia pode significar: realeza, soberania, reino (Lothar COENEN e Colin BROWN, 2000). Já a expressão: Basileia tou theou corresponde a Reino de Deus, é melhor traduzida por reinado de Deus (Thomas RAUSCH, 2006), e baseada na construção cristológica pode ser concebida como o reinado de Jesus. Trata-se do reinado do Deus- homem, capaz de mudar o ser humano, em sua dimensão ontológica e social, sendo mais do que uma expectativa escatológica em relação a sua parousia, mas a uma realidade capaz de transformar indivíduos e sociedades em tempo presente.

9 Dentro das configurações escatológicas, o Reino é uma realidade universal e espiritual, presente e futura (David BOSCH, 2002; Oliver BUSWELL, 2005) capaz de se manifestar no íntimo do homem como na sociedade (Leonardo BOFF, 2012; Jürgen MOLTMANN, 1987). Sob essa perspectiva, "transparece de forma clara que não se deve especular sobre o quando e o como da realização do Reino, pois ele já é vivenciado diariamente, visto que está no meio das pessoas" (Haroldo REIMER e Ivoni RICHTER REIMER, 2008, p. 858).
} 
de esperança equivale a criticar o presente (Juan YODER, 1975). Sob essa perspectiva, o resultado da carreira de Jesus mostra que, de forma preferencial sua proclamação a respeito da basileia foi política ${ }^{10}$, não metafórica e muito menos 'espiritual' (Bruce MALINA, 2004, p. 11) em um sentido restrito. Em síntese, a basileia tou theou se constitui em "uma instituição política que não procede deste mundo. Um sistema de poder celeste, que propõe a configuração de uma alta política que se manifesta na terra" (Danilo GUERRA, 2018, p. 120).

Para Elisabeth Schüssler Fiorenza (2005, p. 159),

Jesus e seus primeiros discípulos anunciavam a basileia (comunidade/ império) como uma realidade alternativa a basileia romana. Dessa forma, além de evocar a ancestralidade que proclama o poder criador e salifico de Deus, o termo basileia também é um símbolo político que apelava à imaginação de oposição do povo vitimizado pelo sistema imperial romano. Ele concebe um mundo alternativo livre de fome, pobreza e da dominação.

A essência do Reino de Deus está em suas rupturas com as estruturas desse mundo, sendo boa notícia somente para os que se convertem (Leonardo BOFF, 2012). Essa essência proporciona a realização da utopia de uma libertação global, estrutural e escatológica, tendo início nesse mundo com Jesus entre os pobres, doentes e marginalizados (Jürgen MOLTMANN, 1987). Dentro dessa categoria marginalizada, as mulheres são maioria"11 (Ivoni RICHTER REIMER, 2006b). Estas, ao serem inseridas

10 Na concepção de Bruce Malina (2004, p. 77) "o Reino de Deus proclamado por Jesus era uma instituição política na qual religião e economia estavam inseridas”. Contudo, a basileia de Cristo não se restringe as articulações políticas convencionais. Ela se instaura no âmbito das relações humanas na forma de uma alta política em relação à ordem política vigente no mundo dos homens (Danilo GUERRA, 2018). Segundo Sherman (apud Philip MOILA, 1990, p. 92) o Reino "abrange a dimensão pré-política, a política e a traspolítica da existência". Para elevar na consciência o significado político de basileia, Elisabeth Schüssler Fiorenza (2005) sugere que a expressão seja melhor traduzida por palavras como "império, domínio ou comunidade". Essas traduções acentuam linguisticamente o caráter oposicional do Império/comunidade de Deus ao Império Romano.

1 Segundo Ivoni Richter Reimer (2006b, p. 38), a hermenêutica feminista não trata de uma oposição ou concorrência entre pobres e mulheres. "Trata-se isto sim, de visibilizar a maior parte dentre os pobres que clamam, ou seja, as mulheres. Trata-se de nomear os sujeitos históricos e hermenêuticos que vão despontando nas práticas da história e devolver-lhes o corpo negado pela historiografia". 
no Reino, encontram em Jesus outra forma de viver, mesmo em um contexto patriarcal (Ivoni RICHTER REIMER, 2011).

A partir dessa realidade agregadora e desviante ${ }^{12}$ da basileia, observamos o aparecimento das comunidades desviantes. Nessas comunidades, homens, mulheres, idosos e crianças não participam da basileia apenas com palavras vazias, mas com poder dinâmico (Haroldo REIMER e Ivoni RICHTER REIMER, 2008).

Este poder dinâmico do Reino de Deus rompe com mecanismos de discriminação, desmascara e desempodera sistemas de injustiça. Este poder acolhe crianças, mulheres e homens em forma igualitária e capacita estas pessoas para serem sujeito de uma nova história, na qual a justiça solidária cuida da vida toda e de cada vida (Haroldo REIMER; Ivoni RICHTER REIMER, 2008, p. 858-859).

Assim, a realidade emancipatória da basileia é o lugar daqueles(as) que seguem a Cristo. Ela fala de bem-estar e de liberdade para todos(as) na aldeia global (Elisabeth SCHÜSSLER FIORENZA, 2005, p. 162). É essa realidade de contrapocisionamentos que foram anunciados por vozes masculinas e femininas no contexto dos cristianismos originários.

Sob essa perspectiva, o kerigma desse Reino que se propõe de forma antagônica aos paradigmas de dominação do século I pode ser analisado no contexto do Evangelho de Lucas. Na sequência, observaremos como a práxis e o anúncio libertador da basileia tou theou interferiu na realidade cotidiana da comunidade lucana, especialmente na vida e na voz das mulheres.

\section{PONTO DE PARTIDA: A NARRATIVA DE LC 8,1-3}

As narrativas bíblicas são frutos do lembrar aquilo que é representativo. Na definição de Ivoni Richter Reimer (2012), os Evangelhos são reconstruções, produtos da memória e das experiências dos indivíduos e comunidades naquele tempo. Nesse sentido, "a história de Jesus foi passada pelo filtro das comunidades, buscando responder suas inquie-

12 De acordo com Ekkhard Stegemann e Wolfgang Stegemann (2004, p. 279), “o comportamento do desviante é definido em cada caso pela sociedade majoritária” Essa sociedade impõe limites e regras para a preservação de sua própria identidade. 
tações, problemas, vocações e desafios específicos" (Ivoni RICHTER REIMER, 2012, p. 238).

Segundo Sandra Pesavento (2006), a memória é uma narrativa de reconfiguração temporal, uma representação de um acontecido, um processo transacional, em que o sujeito se liga com o social. Nele, atribui-se veracidade à recordação por uma operação de reconhecimento de uma experiência passada, resgatada pelo ato de lembrar. A memória conforta, satisfaz, é aceita, passando a ter foros de indiscutível.

Tendo isso na 'memória', observaremos o Evangelho lucano, considerando o que Louis Martyn (1979) chama de duplo nível de testemunho do texto: o que envolve a época de Jesus e o que envolve a época das comunidades onde os textos neotestamentários foram produzidos. Nesse sentido, nossa leitura sempre considerará essa fusão de temporalidades dentro da narrativa. De acordo com a perícope Lc 8,1-3:

E aconteceu, depois disto, que andava de cidade em cidade, e de aldeia em aldeia, pregando e anunciando o evangelho do reino de Deus; e os doze iam com ele, E algumas mulheres que haviam sido curadas de espíritos malignos e de enfermidades: Maria, chamada Madalena, da qual saíram sete demônios; E Joana, mulher de Cuza, procurador de Herodes, e Suzana, e muitas outras que o serviam com seus bens $($ LC 8,1-3).

A configuração textual dessa narrativa nos mostra vários aspectos significativos. Desde já, salientamos que não iremos analisá-la apenas sob o ponto de vista do 'serviço' ou colaboração das mulheres no ministério de Jesus. Compreendemos que essa passagem também fala sobre o Reino de Deus e sua relação com os seguidores(as) do Cristo.

Lucas 8,1 inicialmente fala sobre a questão kerigmática, envolvendo a prática e o anúncio do Reino de Deus por parte de Jesus e dos seus seguidores, os doze. Aqui cabe uma primeira análise: Por que o autor menciona em primeira mão o vínculo de Jesus com os doze apóstolos?

A resposta a essa indagação talvez esteja na importância da tradição apostólica dentro do panorama de formação e estabelecimento das organizações eclesiásticas cristãs entre fim do século I e início do 
séc. II d.C. ${ }^{13}$. Nesse contexto, os autores lucanos, provavelmente sob uma tentativa de autopreservação e de conexão com a tradição apostólica institucionalizada, resolveram dar primeiro crédito aos doze na construção da narrativa.

No entanto, Ivoni Richter Reimer (2011a), baseando-se em textos bíblicos, afirma que havia apóstolas dentro das comunidades dos cristianismos originários, e que inclusive Maria Madalena e Joana faziam parte desse grupo ${ }^{14}$ que anuncia o ressurreto. Segundo Angelo Lancellotti e Giovanni Boccali (1983, p. 98), Joana "é citada outra vez, sempre em Lucas $(24,10)$, entre as mulheres que foram as primeiras testemunhas da ressureição". Dessa forma, "as mulheres são por certo ministras do Evangelho" (Angelo LANCELLOTTI e Giovanni BOCCALI, 1983, p. 98).

De acordo com Ivoni Richter Reimer (2011a, p. 116):

A base constitutiva da identidade cristã é a confissão de que Jesus de Nazaré é o Messias de Deus, que viveu colocando sinais do Reino de Deus [...] Cruz e ressurreição tornam-se marcas representativas da identidade cristã. O que garantiu isto foram o testemunho e o anúncio apostólicos. Apóstola é uma pessoa escolhida e incumbida de realizar uma ordem expressa de quem a escolheu. Quem são, então, testemunhas e apóstolos da ressurreição de Jesus?

Aqui, partimos para outra indagação: se haviam mulheres apóstolas nessa época, porque as mesmas não foram mencionadas com o título de apóstolas em Lc 8,1-3? Há, nesse sentido, um víeis patriarcal implícito no colegiado dos doze? Isso não poderemos responder agora. O que sabemos é que a concorrência em torno da primazia apostólica não é algo pós-canônico, mas sim que "já se fazia presente nos textos bíblicos” (Ivoni RICHTER REIMER, 2011a, p. 118).

13 Sobre a formação da tradição apostólica e o processo de institucionalização da igreja cristã ver em Senén Vidal (2013) e Raymond Brown (1983).

14 Segundo Ivoni Richter Reimer (2011a, p. 118), no decorrer da história eclesiástica, as tradições petrina e paulina sobrepujaram as tradições do apostolado de Maria Madalena, Salomé, Maria de Tiago, Joana... O resultado deste processo foi a lenta, gradativa e incisiva exclusão das mulheres do apostolado e conseqüentemente também de ministérios eclesiais e pastorais ordenados, o que perdura até hoje em algumas igrejas do e no mundo inteiro. 
Na sequência, em Lc 8,2, observamos o destaque para as atividades taumatúrgicas ${ }^{15}$ de Jesus. Para Ivoni Richter Reimer (2011b), nosso corpo é um órgão político-social. Nele se reflete nossa realidade, com ele experimentamos o mundo. No corpo é o lugar onde estão gravadas as marcas do que nos acontece, as marcas da nossa história. Nesse sentido, a relação curativa entre Jesus as mulheres mostra sua proximidade e aponta o seu propósito em relação a elas: aquelas que vivenciaram a cura podem também proclamá-la.

De acordo com Charles L'eplattenier (1993, p. 84), “Lucas não hesita em sublinhar esse fato desde já, com pormenores e nomes. Trata-se de beneficiárias da salvação enquanto bem inestimável da saúde restituída". Nesse versículo os autores lucanos trazem uma perspectiva de visibilização de personagens femininos, uma reafirmação identitária e inclusiva em relação ao movimento de Jesus e o anúncio do seu Reino. A menção de nomes como o de Maria Madalena, Joana e Suzana, em Lc 8,2-3 é significativa nesse sentido. Elas fazem parte da estrutura da basileia, e contribuem com ela não somente com os seus bens.

No entanto, segundo Fritz Rienecker (2005, p. 122), a narrativa lucana não evidencia o caráter kerigmático da pregação feminina no contexto do Reino. Para ele:

Na presente breve passagem são citadas pelo nome não os discípulos que acompanhavam Jesus e os apóstolos nas viagens, como antes, mas as discípulas. Serviam ao Senhor e a seus discípulos com seus bens. Mulheres de posses, portanto, cuidavam do sustento material. Não se fala aqui de um serviço de pregação da mulher.

Aqui aparece a problemática das políticas de interpretação apresentadas por Elisabeth Schüssler Fiorenza ${ }^{16}$ (2005). Para a autora, o discurso

15 Dentro do contexto neotestamentário das curas, Eduard Lohse (2000, p. 216) fala importância dos acontecimentos milagrosos, estes "ocorriam através de pessoas dotadas de poderes especiais, que irradiavam força divina”. Sobre essa temática, ver também Ivoni Richter Reimer (2011).

16 Elisabeth Schüssler Fiorenza (2005, p. 29-52) faz uma crítica à política da interpretação do Jesus histórico como fruto de concepções positivistas, androcêntricas e eurocêntricas. No entanto, aqui se levanta a possibilidade de um modelo alternativo de reconstrução histórica. Sob esse aspecto, ao invés de se optar por uma retórica empirista e kyriocêntrica busca-se uma visão reconstrutiva igualitária e emancipatória das wo/men feita a partir de uma hermenêutica da suspeita. 
interpretativo positivista e androcêntrico sobre o Jesus histórico em relação às mulheres também está embrincado de tendências patriarcais e dominadoras responsáveis pelo silenciamento e invisibilização das mesmas nos textos bíblicos. Nesse aspecto, há uma crítica do emprego hermenêutico sob o viés patriarcal e silenciador das personagens femininas inseridas nas escrituras. É esse tipo de concepção interpretativa que tem causado efeitos históricos e cristalizado mentalidades androcêntricas delimitadoras de espaços e papéis entre homens e mulheres até os dias atuais.

Porque as mulheres não poderiam pregar o que elas viviam? Seria a pregação do Reino de Deus um monopólio masculino, restrito ao colégio dos doze? No entanto, devemos nos atentar para o seguinte:

No caso de $L c 8,3$, devido a uma expressão complementar ao verbo principal, o texto comumente é traduzido por '... e elas o serviam com seus bens'. Esta é uma forma de reduzir o trabalho diaconal de mulheres a questões financeiras, pecuniárias, materiais, de assistência. Contudo, uma melhor tradução da expressão grega pode ser oferecida como '... e elas o serviam de acordo com suas possibilidades', o que remete tanto a potenciais intelectivos, psicológicos, espirituais e materiais. Nesse sentido, diaconia readquire seu status e sentido original de conjunto de ações que implicam 'trabalho de Mesa' no esforço de aliviar situações de sofrimentos e 'trabalho da Palavra' no anúncio testemunhal-intelectivo, no ensino e no acompanhamento espiritual (Ivoni RICHTER REIMER, 2011a, p. 113).

Não há como excluirmos as mulheres e suprimirmos a sua voz em relação à função proclamatória do Reino de Deus. Elas não eram restritas a 'papel' de 'mantenedoras' do ministério de Jesus, pelo contrário, faziam parte dele. Nesse contexto, Joana se torna um personagem intrigante, na medida em que representa a mulher que, mesmo em meio às estruturas patriarcais, tinha em si capacidade e autonomia para decidir o seu próprio destino, no caso, o caminho do Cristo.

Outro problema em relação à política de interpretação sob o viés patriarcal é a existência de uma hermenêutica valorativa, que 'admira', ou vitimiza as mulheres, mas não as empodera, nem altera as paisagens de desigualdade e as relações de poder estabelecidas. Interessante é 
notar que nessa senda interpretativa acabamos sendo reféns de nossas próprias consciências independentes do tempo em que vivemos. Nesse sentido, o processo a política interpretativa silenciadora e invisibilzatória das mulheres, não é responsabilidade apenas da antiguidade ${ }^{17}$, mas dos sujeitos interpretantes ao longo da história, inclusive do hoje.

Em relação a nossa pesquisa, o Evangelho lucano é o documento à espera de novos olhares e interpretações que possam encontrar nas mulheres participantes do movimento de Jesus todas as virtudes nelas existentes. Mas não apenas isso. Em nossa investigação, estamos em busca de caminhos exegéticos que visibilizem, empoderem e não mais desassociem a imagem e a voz feminina da pregação e proclamação do Reino de Deus. No entanto, infelizmente esse ainda é um caminho marginal para interpretação.

\section{A VIDA DE JOANA: UMA ANÁLISE DE GÊNERO}

No panorama da investigação acadêmica, a utilização das perspectivas de gênero ${ }^{18}$ se faz fundamental para a busca e construção de uma hermenêutica visibilizatória das mulheres no contexto neotestamentário. Com o auxílio da categoria analítica ${ }^{19}$ gênero, a pesquisa feminista tem a

17 Um exemplo dessa política interpretativa pode ser observado nas obras de Plutarco (séc. I-II d. C). O filósofo declarava: "respeito à virtude das mulheres" (PLUTARCO, 1987, p. 265). Aqui, compreendemos que diante da mentalidade androcêntrica da maioria dos escritores da antiguidade, o olhar de Plutarco que de alguma forma valorizava a figura da mulher, enfatizando suas virtudes, sua coragem, audácia, fidelidade, bondade, honra e inteligência. No entanto, essa declaração nos leva a questionar até que ponto esse discurso possuía um viés emancipatório em sua realidade.

18 Na concepção de Ivoni Richter Reimer (2005, p. 26), gênero trata-se de uma categoria analítica que "enfatiza o caráter social das distinções construídas a partir das diferenças biológico-sexuais". Para Scott (1995, p. 86), "o gênero é um elemento constitutivo de relações sociais baseadas nas diferenças percebidas entre os sexos [...] é uma forma primária de dar significado às relações de poder”. Segundo Elisabeth Schüssler Fiorenza (2005, p. 92), “o gênero como prática discursiva sociopolítico-religiosa produz diferenças não somente de sexo, mas também de raça, de classe, de preferência sexual, de cultura, de religião, de idade e de nacionalidade".

19 De acordo com Ivoni Richter Reimer (2005, p. 27), "podemos dizer que a categoria de gênero ajuda a entender que as diferenças biológicas não servem para explicar as diferenças de gênero, classe e etnia, mas que estas são culturalmente construídas e se expressam e reproduzem nas múltiplas relações sociais [...] Em Tais relações a questão e a dinâmica de poder e mudança são fundamentais". A “categoria de gênero possibilita que nossas experiências cotidianas sejam levadas a sério como fonte e reflexão teológicas, como processo decisório de exercício 
função de desobstruir o caminho para um 'outro' e novo olhar sobre a história (Luise SCHOTTROFF, 2008). Nesse sentido, a utilização de uma hermenêutica feminista pode resgatar um víeis histórico sempre existente, através da 'exegese do silêncio'²0. Nesse processo analítico não se enaltece a figura feminina em prol de uma depreciação masculina, pois:

Colocar mulheres no centro, no contexto de uma sociedade dominada por homens não significa [...] que um horizonte centrado em mulheres deveria suplantar um horizonte centrado em homens. Não se trata de uma discriminação invertida [...], antes se trata de fazer falar pessoas que não têm voz (Elizabeth BROOTEN apud Luise SCHOTTROFF, 2008, p. 163).

Sob essa matriz teórica, a obra lucana pode ser vista como o Evangelho das mulheres. Segundo Adela Ramos (2003, s/p):

O interesse pelas mulheres lucanas provém essencialmente de um dado textual: o duplo trabalho de Lucas (Evangelho e Atos) contém textos que evocam as mulheres mais do que qualquer outro escrito do Novo Testamento. Além disso, o Evangelho de Lucas contém mais de vinte referências a mulheres que não tem paralelo nos outros evangelhos. Isto levou alguns a considerar Lucas como 'evangelista da mulher'.

Nas palavras de Mauro Orsatti (2000, p. 105):

No terceiro Evangelho a mulher conhece uma substancial promoção [...] se Lucas fala mais sobre as mulheres e aponta-lhes um papel

da cidadania" (Ivoni RICHTER REIMER, 2000, p. 23). Segundo Ivone Gebara (2000, p. 105), "A diferença de gênero é uma diferença entre uma multiplicidade de diferenças que se entrecruzam. Precisamente por isso, a mediação de gênero constitui um instrumento importante para compreender, através de um meio diferente, a complexidade das relações humanas. É um instrumento que tem em vista a transformação das relações sociais. Tornou-se, particularmente nas ciências humanas, não apenas um instrumento de análise, mas um instrumento de auto construção feminina e de tentativa de construção de relações sociais fundadas na justiça e na igualdade, a partir do respeito pela diferença".

20 "A historiografia feminista precisa quebrar o silêncio das fontes androcêntricas e romper com sua interpretação androcêntrica" (Luise SCHOTTROFF, 2008, p. 162). Isso é o que Carla Ricci (apud Luise SCHOTTROFF, 2008) chama de "exegese do silêncio". 
significativo, pretende com isso demostrar que o amor de Deus em Cristo é dirigido a todos [...] ao homem e à mulher, abolindo antigos privilégios e superando injustas diferenças.

Algumas dessas mulheres podem ser vistas em Lucas 8,1-3, como agentes promotoras de novas perspectivas em relação à paisagem social, principalmente por estarem associadas ao movimento revolucionário de Jesus. Sob o viés da narrativa lucana vemos a identificação da personagem Joana em meio ao grupo dos que seguiam Jesus e proclamavam as boas novas do Reino. Inserida nesse movimento, Joana é um dos exemplos de muitas mulheres que possuíam voz ativa, sendo sujeitos de sua própria história na época dos protocristianismos.

O texto lucano nos mostra que Jesus tinha seguidores até mesmo no palácio de Herodes. Nesse espaço de poder se encontra Joana, esposa de Cuza, uma mulher que, diferente da maioria das seguidoras de Jesus, possuía prestígio e influência social (Russel CHAMPLIM, 1979, p. 81). Todavia, Joana vivia em uma atmosfera cultural mediterrânea patriarcal, onde um status social alto ou baixo e as oportunidades de vida como um todo eram facilitadas também pela pertença de uma pessoa a um gênero (Ekkhard STEGEMANN; Wolfgang STEGEMANN, 2004, p. 85). Nesse aspecto, não em vias de regra, a maioria das mulheres não usufruía de status social, e no máximo gozava do status do marido ${ }^{21}$.

Joana também viveu sob a realidade de um mundo antigo que se organizava distribuindo papéis teologicamente ${ }^{22}$ condicionados aos atores sociais. Dentro dessa hermenêutica social, as mulheres quase sempre eram restritas ao ambiente privado, pois, "a divindade desde o princípio, adaptou a natureza da mulher aos trabalhos e assuntos internos e a do homem aos externos" (Ekkhard STEGEMANN; Wolfgang STEGEMANN, 2004, p. 415).

${ }^{21}$ Dessa forma, oferece-se, por um lado, a possibilidade de associar mulheres a um determinado estrato via seus maridos ou pais. Sem dúvida, pode-se afirmar que basicamente as mulheres (e crianças) participavam do respectivo status de seus esposos ou pais (Ekkhard STEGEMANN e Wolfgang STEGEMANN, 2004, p. 86).

22 Ivoni Richter Reimer (2006a) trata sobre a dominação baseada na desigualdade ideologicamente estipulada como 'natural' entre Deus e as pessoas, governantes e governados, pais e filhos, espírito e corpo. 
Sob essa perspectiva 'estratigráfica' em relação às mulheres, o predomínio ideológico patriarcal e a economia ${ }^{23}$ doméstica do mundo mediterrâneo do século I baseavam-se em argumentos como o de Aristóteles ${ }^{24}$. O ideólogo afirma que:

A providência divina criou os homens mais fortes do que as mulheres, pois o homem precisa defender o lar, a mulher "temerosa" deve cuidar dele. Ela foi, de resto, abençoada com a paciência necessária para o trabalho manual e é responsável pela alimentação das crianças, enquanto ao homem cabe educá-las (ARISTÓTELES apud Ekkhard STEGEMANN; Wolfgang STEGEMANN, 2004, p. 415).

Dentro desse contexto, em meio a uma estrutura de papéis socialmente condicionados observada naquela época, qual seria o papel de Joana? Ela estaria dentro dos pressupostos sociais 'naturais' estabelecidos em relação ao 'lugar' de homens e mulheres, ou seria um exemplo de subversão a essa realidade? Como seria possível a mulher de um funcionário de um 'outro reino ${ }^{25}$ ' viver a realidade do Reino de Deus ao seguir Jesus estrada afora?

Diante dessas indagações a pesquisa de Ivoni Richter Reimer (2011a, p. 111) sobre as mulheres e o movimento emancipatório de Jesus, mostra-nos um caminho de reflexão. Segundo a autora:

[...] uma das formas desse seguimento era justamente o chamado de Jesus a que essas pessoas abandonassem tudo, bens e propriedades,

23 Sobre o jeito romano de 'organizar a casa' ver Ivoni Richter Reimer (2006a, p. 72-97).

24 Aristóteles afirma que: "a ciência da economia doméstica tem três ramos- um trata das relações entre senhor e escravo, outro das relações entre pai e filhos e outro das relações entre marido e mulher, pois faz parte da economia doméstica o comando da mulher e dos filhos pelo chefe da família" (ARISTÓTELES, 1985, s/p). Entretanto, mesmo que esse discurso de comando por parte do 'chefe da casa' possua em si um pressuposto que envolve linhas de democracia em relação à figura da esposa, o mesmo está longe de ser uma tentativa emancipatória. Neste tocante, é interessante observar que intérpretes cristãos, na história da igreja, faziam referências as expressões ideológicas e patriarcais de ideólogos como Aristóteles e Cícero. Um desses intérpretes foi Agostinho. Para maiores informações ver em Ivoni Richter Reimer (2006a, p. 72-97).

25 Quando nos referimos a outro reino nos reportamos ao conflito entre o reino de Deus e o "mundo", o sistema espiritual maligno de poderes que se manifesta material e simbolicamente através de dispositivos teatrocráticos e latreocráticos ao longo dos tempos e sociedades. No caso específico da narrativa lucana, o mundo se manifesta na casa de Herodes. Acerca desse tema cf. Danilo Guerra (2018, p. 147-234). 
família e relações dominadoras anteriores, a fim de que estivessem livres para o amor a serviço do Reino de Deus. Trata-se do movimento profético itinerante de Jesus que agregava e congregava também muitas mulheres (LC 8,1-3) que em Jesus encontraram outra forma de viver sua vida no contexto patriarcal do Império Romano e de culturas religiosas patriarcais. Neste movimento de renovação intrajudaico, elas eram consideradas iguais, discípulas, libertas, agraciadas pelo amor de Deus e que largavam suas antigas formas de vida para se colocar no seguimento a Jesus.

O Reino de Deus é uma realidade que rompe paradigmas. É preciso observar que Maria Madalena, Joana e Suzana estavam fora de suas casas cooperando e anunciando a basileia na esfera pública, contrariando os critérios da economia doméstica do seu tempo.

A partir da perspectiva de gênero encontramos na figura de Joana, um perfil que não se adequa aos padrões da economia doméstica refletido por ideólogos da antiguidade. Em Joana, observamos a adesão a um movimento consolidado sobre um fundamento teológico não legitimador, mas questionador das injustiças e desigualdades. Sob os princípios da basileia tou theou, o movimento de Jesus rompe com as estruturas convencionais dos estratos, status e economia doméstica de sua época. Dessa forma, apesar de frequentar o status superior de uma sociedade estratificada, hierarquizada dentro de configurações patriarcais, ao ser inserida esfera da basileia, Joana vive uma realidade de contrapocisionamentos.

Em Joana, percebemos o caráter heterotópico ${ }^{26}$ do Reino de Deus (Wolfgang STEGEMANN, 2012; Danilo GUERRA, 2015; 2018). Este se faz gerador de consciências, posicionamentos e atitudes outras em meio a uma sociedade aparentemente cristalizada em suas relações de poder. Ao se apropriar desse caráter desviante, Joana nos mostra que, ao longo dos tempos, sempre houve mulheres que não tinham o perfil adaptado à chamada condicio naturae, teologicamente legitimada por paradigmas

26 Segundo Wolfgang Stegemann (2012, p. 414), o termo heterotopia serve como “designação para o conteúdo das esperanças vinculadas ao Reino de Deus”. Nesse sentido, o Reino de Deus possui um caráter de contraposicionamentos que reporta a uma "esperança por uma ordem social e sociopolítica claramente diferente, mas em princípio realizável (e por um poder político com condições de levar a efeito tal ordem heterotópica)" (Wolfgang STEGEMANN, 2012, p. 414). 
androcêntricos e patriarcais vigentes. Pelo contrário, sob uma postura de resistência estas construíram vez e voz para influenciar e alterar a paisagem social, política e religiosa de sua época.

\section{CONCLUSÃO}

No decorrer deste artigo, procuramos estabelecer nuances para uma dynamis provocativa no tocante aos enredos e tramas que circundam as potencialidades da voz feminina da antiguidade a contemporaneidade. Como matriz geradora ou como portadora das mensagens oriundas das convicções, intencionalidades e sentimentos dos mais diversos, esta ferramenta, desde os tempos remotos, tem sido tanto reverberada quando silenciada na dialética do poder circulante nos orquestramentos societais de matização patriarcal.

Diante deste cenário, são plasmadas de forma heterotópica as vozes femininas da basileia na esfera das narrativas neotestamentárias, especificamente, do Evangelho de Lucas, nosso recorte exegético. Esse núcleo paradigmático revolucionário evidencia que o Reino de Deus no Evangelho de Lucas é para todas (os). Seu alcance se reflete na vida e na decisão de mulheres e homens. Nesse aspecto, a atitude de Joana, membro e partícipe das construções ideológicas do Reino traz visibilidade para a real possibilidade da proclamação feminina da basileia tou theou.

Talvez seja difícil admitirmos a existência de vozes que desestabilizam estruturas sócio-políticas e retiram o sujeito interpretante de sua zona de conforto patriarcal, confrontando sua política de interpretação dos textos bíblicos. Mas a realidade histórica continua batendo à porta, à espera de simplesmente ser mostrada como realmente 27 aconteceu.

Nessa busca, a utilização da categoria analítica gênero nos permitiu escutar a voz de Joana na narrativa lucana, e, nesse aspecto, resgatar a memória dessa mulher como agente audível e ativo no movimento de Jesus. No contexto lucano, observamos em Maria Madalena, Joana,

27 Como seria a história contada sob o olhar das mulheres no seu tempo? Essa pergunta está aberta a novos olhares e pesquisas sob essa realidade ainda um tanto encoberta. A priori podemos afirmar que "nosso passado ainda se constrói através de discursos bastantes conservadores e androcêntricos, ainda que exista uma grande quantidade de fontes, literárias ou principalmente materiais, á espera de novas interpretações" (Marina CAVICCHIOLI, 2003, p. 294). 
Suzana e tantas outras o ecoar de vozes que decidem entregar suas vidas em prol de uma missão que proclama igualdade e justiça entre os seres humanos. Nesse enredo, as vozes destas mulheres se fazem vozes da basileia. Nesse sentido, o anúncio feminino do Reino de Deus se faz sonoro. Resta-nos escolher ouvi-lo e repercuti-lo. Contudo, estamos frente a uma longa caminhada interpretativa e ativa, rumo à destituição dos protagonismos e vitimizações exacerbados (Ivoni RICHTER REIMER, 2013). Uma caminhada que não trilha a trajetória para a construção de paradigmas em relação ao gênero, mas que leva a equiparação e, sobretudo ao amor e respeito a todos os seres humanos. Esses valores cristotópicos se encontram no kerigma do Reino de Deus.

\section{REFERÊNCIAS}

ARISTÓTELES. Política. Tradução de Mário da Gama Kury. Brasília: Editora Universidade de Brasília, 1985.

BOSCH, David J. Missão Transformadora. Tradução de Geraldo Korndörfer e Luís Marcos Sander. São Leopoldo, RS: Sinodal, 2002.

BOFF, Leonardo. Jesus Cristo libertador: ensaio de cristologia crítica para o nosso tempo. Petrópolis: Vozes, 2012.

BOURDIEU, Pierre. A dominação masculina. 3 ed. Rio de Janeiro: Bertrand Brasil, 2003. BROWN, Raymond E. A comunidade do discípulo amado. Tradução de Euclides Carneiro da Silva. São Paulo: Paulinas, 1983.

BULTMANN, Rudolf. Teologia del Nuevo testamento. Tradujo Víctor A. Martinez de Lapera. Salamanca: Ediciones Sígueme, 1981.

BUSWELL, J. Oliver. Jr. Teologia Sistemática: Tomo IV, Escatologia. Tradução de J. Lourdes Ramírez. Miami: Logoi, 2005.

CAVICCHIOLI, Marina Regis. A posição da mulher na Roma Antiga: do discurso acadêmico ao ato sexual. In: FUNARI, Pedro Paulo A; FEITOSA, Lourdes Conde; SILVA, Glaydson José da. (Org.). Amor, desejo e poder na Antigüidade: relações de gênero e representações do feminino. Campinas: Editora da Unicamp, 2003. p. 287-295.

COENEN, Lothar; BROWN, Colin. Dicionário Internacional de Teologia do Novo Testamento. 2 vols. 2 ed. São Paulo: Vida Nova, 2000.

DODD, Charles Harold. Las parabolas del reino. Madrid: Ediciones Cristiandad, 1974.

FOUCAULT, Michel. Outros espaços. In: Estética: literatura e pintura, música e cinema. Tradução de Inês Autran Dourado Barbosa. Rio de Janeiro: Forense Universitária, 2009. p. 411-422. 
FOUCAULT, Michel. Microfisica do poder. São Paulo: Graal, 2012.

GADAMER, Hans-Georg. Verdade e Método I: traços fundamentais de uma hermenêutica filosófica. Tradução de Flávio Paulo Meuer. Petrópolis: Vozes, 1997.

GEBARA, Ivone. Rompendo o Silêncio: uma fenomenologia feminista do mal. Petrópolis: Vozes, 2000.

GOPPELT, Leonhard. Teologia do Novo Testamento. Tradução de Martin Dreher e Ilson Kayser. São Paulo: Editora Teológica, 2003.

GONÇALVES, Ana Teresa Marques. Um olhar sobre Júlia Domna: esposa e mãe de imperadores. In: FUNARI, Pedro Paulo A; FEITOSA, Lourdes Conde; SILVA, Glaydson José da. (Org.). Amor, desejo e poder na Antigüidade: relações de gênero e representações do feminino. Campinas: Editora da Unicamp, 2003. p. 327-354.

GUERRA, Danilo Dourado. O Reino de Deus e o mundo dos homens: em busca da heterotopia joanina. Dissertação (Mestrado em Ciências da Religião) - Pontifícia Universidade Católica de Goiás, Goiânia, 2015.

GUERRA, Danilo Dourado. Heróis em cena: a construção paradigmática contracultual da mesocristologia joanina. Tese (Doutorado em Ciências da Religião) - Pontifícia Universidade Católica de Goiás, Goiânia, 2018.

JEREMIAS, Joachim. Teologia del Nuevo Testamento. Tradução de Constantino Ruiz Garrido. Salamanca: Ediciones Sígueme, 1973.

LANCELLOTTI, Angelo; BOCCALI, Giovanni. Comentário ao Evangelho de Lucas. Petrópolis: Vozes, 1983.

L'EPLATTENIER, Charles. Leitura do Evangelho de Lucas. Tradução de Benôni Lemos. São Paulo: Paulinas, 1993.

LOHSE, Eduard. Contexto e ambiente do Novo Testamento. Tradução de Hans Jörg Witter. São Paulo: Paulinas, 2000.

MARTYN, J. Louis. History \& Theology in the Fourth Gospel. Nasville: Abingdon, 1979. MOILA, Philip. Reinado de Deus e compromisso político. Estudos Teológicos, São Leopoldo, p. 83-97, 1990.

MOLTMANN, Jürgen. La Iglesia, Fuerza del Espiritu. Tradução de Emilio Saura. Salamanca: Ediciones Sígueme, 1978.

NÚÑEZ, Emilio Antônio. La natureza del Reino de Dios. In: PADILLA, C. Rene (Org.). El Reino de Dios y America Latina. Buenos Aires: Casa Bautista de Publicaciones, 1975, p. $17-42$.

ORSATTI, Mauro. Lucas: Evangelho no feminino. Tradução de João Batista Boaventura. Aparecida: Editora Santuário, 2000.

PANNENBERG, Wolfhart. Teología y reino de Dios. Salamanca: Sígueme, 1974. 
PESAVENTO, Sandra Jatahy - Palavras para crer. Imaginários de sentido que falam do passado. In: Nuevo Mundo Mundos Nuevos. Debates, 2006. Disponível em: <http:// nuevomundo.revues.org/1499>, acesso em: 28 de Março 2014.

PLUTARCO. Obras Morales e de costumbres: virtudes de mujeres. Madrid: Editorial Gredos, 1987.

RAMOS, Adela. Las mujeres em el Evangelio de Lucas. Revista de Interpretação Bíblica Latino-Americana, v.1, n. 44, p. 71-86, 2003.

RAUSCH, Thomas P. Quem é Jesus? Uma Introdução a Cristologia. Aparecida: Santuário, 2006.

REIMER, Haroldo; RICHTER REIMER, Ivoni. Reino de Deus. In: FILHO, Fernando Bortolleto. Dicionário Brasileiro de Teologia. São Paulo: ASTE, 2008. p. 855-859.

RIENECKER, Fritz. Evangelho de Lucas comentário esperança. Tradução de Werner Fuchs. Curitiba: Editora Evangélica Esperança, 2005.

RICHTER REIMER, Ivoni. O belo, as feras e o novo tempo. Petrópolis: Vozes, 2000.

RICHTER REIMER, Ivoni. Grava-me como selo sobre o teu coração: teologia bíblica feminista. São Paulo: Paulinas, 2005.

RICHTER REIMER, Ivoni. Patriarcado e economia política: o jeito romano de organizar a casa. In: RICHTER REIMER, Ivoni (Org.). Economia no mundo bíblico. Enfoques sociais, históricos e teológicos. São Leopoldo: CEBI/ Sinodal, 2006a, p. 72-97.

RICHTER REIMER, Ivoni. Bíblia e hermenêutica de classe, gênero e etnia. In: REIMER, Haroldo; SILVA, Valmor da (Org.). Hermenêuticas Bíblicas: Contribuições ao I Congresso Brasileiro de Pesquisa Bíblica. São Leopoldo: Oikos; Goiânia: UCG e ABIB, 2006b, p. 33-48. RICHTER REIMER, Ivoni. Apostolado, diaconia e missão de mulheres nas origens do cristianismo: rever tradições para empoderar e promover cidadania plena. Revista Pós-Escrito. Rio de Janeiro, n,4, p. 110-126, ago./dez. 2011 .

RICHTER REIMER, Ivoni. El milagro de las manos. Sanaciones y exorcismos de Jesús em su contexto histórico-cultural. Navarra: Verbo Divino, 2011b.

RICHTER REIMER, Ivoni. Textos do Novo Testamento como fonte para estudos da história. In: NETO, Dirceu Marchini; NASCIMENTO, Renata Cristina de Sousa (Org.). Idade Média: entre a história e a historiografia. Goiânia: Ed. Da PUC Goiás, 2012. p. 235-252.

RICHTER REIMER, Ivoni. Maria, Jesus e Paulo com as mulheres: textos, interpretações e história. São Paulo: Paulus, 2013.

SCHÜSSLER FIORENZA, Elisabeth. Jesus e a política da interpretação. Tradução de Adail Sobral. São Paulo: Loyola, 2005.

SCHOTTROFF, Luise. Exegese feminista: resultados de pesquisas bíblicas na perspectiva de mulheres. Luise Schottroff; Silvia Schoer e Marie-Theres Wacker. Tradução de Monika Ottermann. São Leopoldo: Sinodal/EST; CEBI; São Paulo: ASTE, 2008. 
SCOTT, Joan Wallach. Gênero: uma categoria útil de análise histórica. Educação e Realidade. Tradução de Guacira Lopes Louro. Porto Alegre, v. 20, n. 2, p. 71-99, jul./dez. 1995. SCHNAKENBURG, Rudolf. Reino e reinado de Dios. Traduccíon de Jose Cosgaya. Madrid: Ediciones FAX, 1967.

SCHLOSSER, Jacques. O reinado de Deus na teologia bíblica. In: LACOSTE, Jean-Yves (Org.). Dicionário crítico de teologia. Tradução de Paulo Meneses. São Paulo: Paulinas; Loyola, 2004. p. 1500-1504.

STEGEMANN, Ekkhard W; STEGEMANN, Wolfgang. História social do protocristianismo: os primórdios do judaísmo e as comunidades de Cristo no mundo mediterrâneo. Tradução de Nélio Schneider. São Leopoldo: Sinodal, 2004.

STEGEMANN, Wolfgang. Jesus e seu tempo. Tradução de Uwe Wegner. São Leopoldo: Sinodal/EST, 2012.

VIDAL, Senén. Jesus, o Galileo. Tradução de Solange do Carmo. São Paulo: Loyola, 2009. VIDAL, Senén. Evangelio y Cartas de Juan: Génesis de los textos juánicos. Bilbao: Ediciones Mensajero, 2013.

YODER, Juan H. La expectativa messiânica del Reino y su caracter central para uma adecuada hermenêutica contemporânea. In: PADILLA, C. Rene. El Reino de Dios y America Latina. Buenos Aires: Casa Bautista de Publicaciones, 1975. p. 113-120. 